\title{
Low-temperature threshold for egg survival of a post-diapause and non-diapause European aedine strain, Aedes albopictus (Diptera: Culicidae)
}

\author{
Stephanie Margarete Thomas ${ }^{1 *}$, Ulla Obermayr ${ }^{2}$, Dominik Fischer ${ }^{1}$, Juergen Kreyling ${ }^{1}$ and Carl Beierkuhnlein ${ }^{1}$
}

\begin{abstract}
Background: The interplay between global warming and invasive arthropods in temperate zones is of utmost interest in terms of the potential expansions of vector-borne diseases. Up to now, investigations on the recent establishment of mosquito vectors have focused on temperatures during their phases of activity. However, cold temperatures may also act as a strong ecological constraint. Projected changes in winter climate indicate an increase of mean minimum temperatures of the coldest quarter, less frequent days with frost and a shorter frostseason in Europe at the end of the century. Nevertheless, single cold extremes are also expected to persist under warming scenarios, which have a strong impact on reproduction success.
\end{abstract}

Methods: Here, the temperature constraints of European Aedes albopictus eggs, which had passed through a diapause, compared to non-diapausing eggs were examined systematically under controlled laboratory conditions. Additionally, one tropical strain of Ae. albopictus and of Ae. aegypti was used in the comparison.

Results: The lower temperature threshold tolerated by the European eggs of Ae. albopictus which have undergone a diapause, was $-10^{\circ} \mathrm{C}$ for long term exposures (12 and $\left.24 \mathrm{~h}\right)$ and $-12^{\circ} \mathrm{C}$ for $1 \mathrm{~h}$ exposure. Non-diapausing eggs of European Ae. albopictus were found to hatch after a $-7^{\circ} \mathrm{C}$ cold treatment $(8,12$ and $24 \mathrm{~h}$ exposure). Both tropical aedine species only tolerated the long term treatment at $-2^{\circ} \mathrm{C}$. Neither Ae. albopictus nor Ae. aegypti eggs hatched after being exposed to $-15^{\circ} \mathrm{C}$. Survival was mainly influenced by temperature $(F=329.2, d f=1, p<0.001)$, whereas the duration of the cold treatment only significantly influenced the hatching response at the thermal limits of survival $(F=5.6, d f=1, p=0.031)$ but not at $0^{\circ} \mathrm{C}(F=0.1, d f=1, p=0.730)$. Hatching success after the cold treatment was significantly increased in European eggs, which have undergone a diapause compared to non-diapausing eggs $(\mathrm{F}=14.7, \mathrm{df}=3, \mathrm{p}<0.001)$. These results illustrate rapid adaptation.

Conclusions: Here, low temperature thresholds for aedine mosquito egg survival were detected. The compilation of risk maps for temperate regions can substantially be improved by considering areas where an establishment of a vector population is unlikely due to winter conditions.

\section{Background}

The interplay between invasive arthropods and global warming is of utmost interest in terms of potential expansions or shifts of vector-borne infectious diseases [1,2]. In Europe, six non-European aedine mosquito species have been found, quite recently Aedes koreicus [3,4]. Almost all were accidentally imported by the used tire trade [4]. Aedes albopictus (Diptera: Culicidae) is a prominent

\footnotetext{
* Correspondence: stephanie.thomas@uni-bayreuth.de

'Department of Biogeography, University of Bayreuth, Universitaetsstrasse 30, D-95447 Bayreuth, Germany

Full list of author information is available at the end of the article
}

example of an invasive arthropod vector. It is a competent vector for 22 arboviruses (among others Chikungunya and dengue) and for Dirofilaria worms [5]. Almost 30 years after the first recorded introduction of this vector to Europe, the first autochthonous cases of Chikungunya [6] and dengue [7] have been detected in southern Europe. Originating from subtropical and tropical regions, the aedine vector has overcome a wide range of continental and oceanic barriers during the last decades [8]. Today, among other regions [9] the European continent is affected by the invasion of this species. Laboratory experiments [10-12] and field observations $[13,14]$ on the climatic 
constraints and on the climate-driven population dynamics of this mosquito have focused on the role of temperature during the phase of larval and adult activity, but rarely during the total life cycle [15]. Mortality of eggs has been examined under different levels of relative humidity and warm temperatures [16]. However, low temperatures during inactive periods may also act as an ecological constraint for the range expansion of mosquitoes [17]. In the case of shifts of populations to higher latitudes, the minimum temperatures and the mean temperature of the coldest month or quarter have been discussed as a proxy for the ecological constraints of Ae. albopictus [18]. But sensitivity against temperature thresholds and the ability to cope with thermal constraints is not a permanent trait during the life cycle of this species. The capability to develop cold-tolerant diapausing eggs under specific environmental conditions is one key factor for Ae. albopictus to establish in higher latitudes [19]. Photoperiod and temperature are known to modulate the production of diapausing and non-diapausing eggs in Ae. albopictus [13,20]. During diapause, desiccation resistance in eggs increases due to higher concentrations of hydrocarbons at the egg surface [21].

Projected changes in winter climate indicate an increase of mean minimum temperatures of the coldest quarter by $2.2-4.2^{\circ} \mathrm{C}$ in south-western Europe, and by up to $4.0-6.4^{\circ} \mathrm{C}$ in northern Europe (IPCC scenario A2, 1961-1990 to 2071-2100) [22]. However, these values do not display changes in absolute minimum temperatures. Furthermore, less frequent days with frost (a decrease of $60-80 \%$ and $30-45 \%$, in south-western and northern Europe, respectively) and a shorter frost-season (a decrease of 35-50\% and $20-30 \%$, in south-western and northern Europe, respectively) are expected at the end of the century [22]. Nevertheless, single cold extremes seem to persist by the end of this century also under warming scenarios because of increasing climatic variability $[23,24]$. These cold spells are usually short term events with a strong impact on the population dynamics of mosquitoes and thus on mosquito-borne disease transmission. Effects are expected especially when late frost events happen to occur in spring [25]. Hence, the influence of short frost events on egg survival when mosquito diapause is already broken is highly relevant for populations to establish and in terms of population dynamics.

Up to now, investigations on the recent establishment of the mosquito vector focused on temperatures during the phases of activity [10-14,16]. However, cold temperatures may also act as a strong ecological constraint in terms of possible range expansions [18]. Winter warming may increase the survival rate of mosquito eggs, but as evidence suggests that climatic variability and extreme temperature events will become more important, reproduction success and population dynamics can also be negatively affected
[26]. As a matter of fact, the minimum temperature constraints of European Ae. albopictus eggs have not yet been systematically examined under controlled laboratory conditions. Because regional invasive populations of the species are known to adapt rapidly to the climatic conditions such knowledge on low temperature constraints is urgently needed. Here, we hypothesized that: (1) the eggs of European Ae. albopictus which have undergone a diapause tolerate minimum temperatures down to $-10^{\circ} \mathrm{C}$, (2) the duration of exposure to frost influences the survival of eggs and (3) hatching success after a cold treatment increases in eggs which have passed through a diapause compared to non-diapausing eggs.

\section{Methods}

\section{Species, strains and standard protocol}

Overall, we tested eggs from two strains of Ae. albopictus (temperate European and tropical Asian origins) and one strain of Ae. aegypti (tropical Asian origin). The European Ae. albopictus strain originated from eggs collected in the field in Rimini (Italy) and reared in the laboratory (Rimini F43). The tropical aedine species were obtained from a long-lasting laboratory colony. Laboratory colonies were used so that further threshold experiments with the same strains could be combined as a basis for epidemiological and environmental modeling.

The temperate strain of Ae. albopictus was artificially introduced to diapause. For all strains, we determined the survival of eggs after being exposed to low temperatures. In a climate chamber trial we applied a gradient of minimum temperatures $\left(0\right.$ to $\left.-15^{\circ} \mathrm{C}\right)$. Each temperature treatment was replicated for different durations (1 to $24 h$ ).

Female mosquitoes were reared according to the standard protocol at a temperature of $27^{\circ} \mathrm{C}$, a relative humidity of $60-80 \%$ and a 12:12 h (L:D) photoperiod. The light period was set from 8:00 to 20:00 and held constant at 150 Lux. After hatching from the eggs, larvae were kept in a water basin $(30 \times 30 \times 10 \mathrm{~cm})$ that was filled with a 1:1 mixture of tap- and deionised water. Larvae were fed with fishfood flakes $\left(\right.$ Tetra $\left.\mathrm{Min}^{\circledR}\right)$. Before adult emergence, the pupae were transferred to a cage $(40 \times 30 \times 20 \mathrm{~cm})$. Adult mosquitoes had constant access to sugar solution ( $10 \%$ dextrose). At the age of seven to ten days after emergence from the pupae, females received their first blood-meal with human blood derived from expired blood preservations. The blood was heated up to $38 \pm 1^{\circ} \mathrm{C}$ and transferred into sheep intestines to be exposed to the mosquito cage population. After three to four days eggs were laid on moistened filter paper, subsequently removed from the cage, left to dry for 2 days and then stored in plastic bags at $27^{\circ} \mathrm{C}$ with a minimum relative humidity of $85 \%$ before being exposed to the frost manipulation. 


\section{Induction of diapausing eggs}

In Ae. albopictus, the production of diapausing eggs is known to be induced by low temperatures and shortened photoperiods [27,28]. According to Hanson and Craig [29], the induction of diapause under laboratory conditions can be achieved by transferring mosquito pupae from rearing conditions at $27^{\circ} \mathrm{C}$ and a $16: 8 \mathrm{~h}$ (L:D) photoperiod to $21^{\circ} \mathrm{C}$ and a $8: 16 \mathrm{~h}$ (L:D) photoperiod. We applied this procedure with some minor modifications: After hatching from the eggs, European Ae. albopictus larvae were kept at a temperature of $27^{\circ} \mathrm{C}$, a relative humidity of $60-80 \%$ and a 12:12 h (L:D) photoperiod until they reached the second instar. The basins were then transferred to a room at $21-22^{\circ} \mathrm{C}, 30-40 \% \mathrm{rH}$ and a $8: 16 \mathrm{~h}$ (L:D) photoperiod [29]. The light period (150 Lux) was set from 8:00 to $16: 00$. In contrast to [29], mosquito larvae were kept at $21-22^{\circ} \mathrm{C}$ and at a $8: 16 \mathrm{~h}$ (L:D) photoperiod as soon as they reached the second instar larval stage. By doing so the chances of diapause induction are increased while overall development is slowed down. Before emergence the pupae were transferred to a cage $(40 \times 30 \times 20 \mathrm{~cm})$ and provided with sugar solution (10\% dextrose). Adults were held under the same conditions and were fed blood after 7-12 days. Eggs were laid on moistened filter paper after three to four days and left to dry for 2 days. They were then stored for 14 weeks in plastic bags at $21-22^{\circ} \mathrm{C}$ with a minimum relative humidity of $60 \%$ until spontaneous hatching occurred again with about $90 \%$.

\section{Treatment}

We manually placed 20 eggs (with each egg inspected under a stereo microscope to exclude capped eggs or those with signs of desiccation) from each Aedes population onto a moist filter paper pad, which was then deposited in a glass vial. This vial was then sealed by a rubber plug to reduce the loss of moisture and, hence to minimize any possible desiccation effects. The experimental design aimed to maximize temperature levels and cold duration in order to determine lethal thresholds as precisely as possible. The eggs were exposed to seven different temperatures: $0^{\circ} \mathrm{C},-2^{\circ} \mathrm{C},-5^{\circ} \mathrm{C},-7^{\circ} \mathrm{C},-10^{\circ} \mathrm{C},-12^{\circ} \mathrm{C}$ and $-15^{\circ} \mathrm{C}$ by using a climate chamber (Licht-Thermostate Typ 1301, RUMED, Rubarth Apparate, Laatzen, Germany). The duration was 1, 4, 8, 12 and 24h (16:8 (L:D) photoperiod) for each temperature treatment, respectively.

\section{Hatching and counting}

After the cold treatment, the eggs were acclimated at room temperature $\left(18-20^{\circ} \mathrm{C}\right)$. The glass vials containing the filter paper pad with 20 eggs were filled with $20 \mathrm{ml}$ of nutrient broth solution (cooled boiled water with the addition of powdered bacto-nutrient broth, $0.1 \%$ in weight, according to Novak and Shroyer [30]). Furthermore, the temperature of the nutrient broth solution was set to $25^{\circ} \mathrm{C}$ to stimulate the hatching response. The submerged eggs of the tropical strains were kept at $25^{\circ} \mathrm{C}$ with a $16: 8 \mathrm{~h}$ (L:D) photoperiod and the eggs of the temperate strains were kept at $20^{\circ} \mathrm{C}$. Hatching at each level of temperature was determined after 12, 24, 48, 72 and 96h. Larvae were removed at these times, respectively. The minimum survival temperature was quantified as the lowest temperature at which successful hatching was observed. The hatching rate was also quantified as a percent for each combination of temperature and duration.

\section{Statistics}

The interaction between temperature level and the duration of exposure on survival was explored by a linear least squares regression of the minimum survival temperature for each category of duration. Inter-specific differences in minimum survival temperature were compared by analyzing the slopes of the linear regression between the duration and the minimum survival temperature. This was evaluated by a Monte-Carlo permutation procedure to compare the true difference in the slope of two strains with the differences in 1,000 permutations of randomly-assembled groups. The importance of temperature and duration on hatching success was further investigated by linear models while using the species/strain identity as a co-variate. Differences between species/strains were evaluated by the same linear models combined with analyses of variance (ANOVA).

Prior to statistical analysis, data were log-transformed if conditions of normality were not met or to improve the homogeneity of variances. Both characteristics were tested by examining the residuals versus fitted plots and the normal qq-plots of the linear models. Statistical analysis was carried out using R 2.12.0 [31] supported by the package simba [32].

\section{Results}

\section{Minimum survival temperature}

The minimum survival temperature tolerated by the European eggs of Ae albopictus after a diapause (Figure 1) was $-10^{\circ} \mathrm{C}$ for long term exposures (12 and 24h), while they survived short term exposure (1h) at $-12^{\circ} \mathrm{C}$. Non-diapausing eggs of European Ae. albopictus were found to hatch even after a $4 \mathrm{~h}$ treatment at $-12^{\circ} \mathrm{C}$. However, with mean and long term exposures $(8,12$ and $24 \mathrm{~h})$ hatching only occurred at less extreme temperatures $\left(-7^{\circ} \mathrm{C}\right)$. The tropical aedine species only differed in its hatch response for the $1 \mathrm{~h}$ cold treatment: While tropical Ae. albopictus survived at $-10^{\circ} \mathrm{C}, A e$. aegypti hatched at $-7^{\circ} \mathrm{C}$. In contrast to the short term exposure to cold temperatures, both species only tolerated the long term treatment at $-2^{\circ} \mathrm{C}$. The minimum survival temperature for different durations of exposure did not differ significantly between strains/species according to the Monte- 


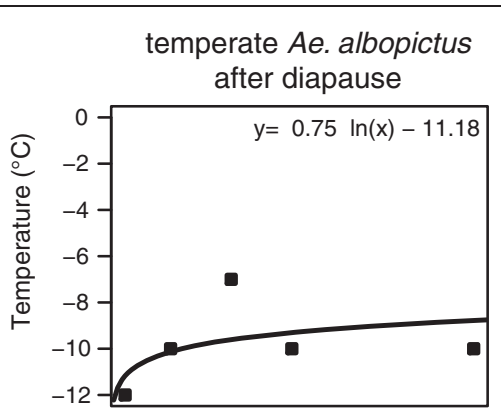

tropical Ae. albopictus

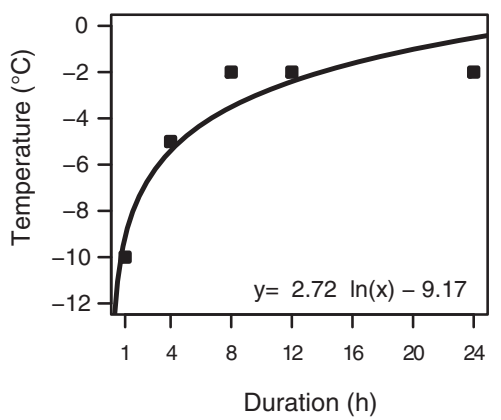

temperate Ae. albopictus

non-diapausing

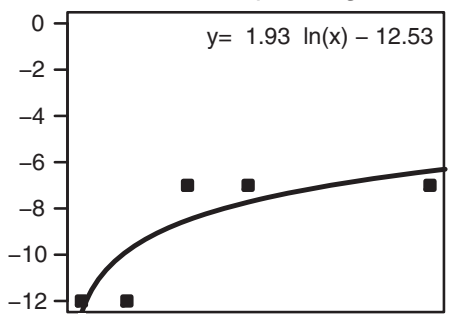

tropical Ae. aegypti

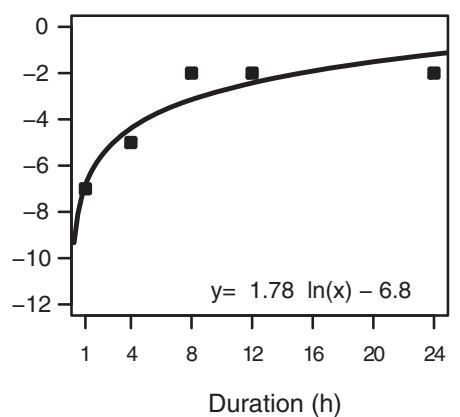

Figure 1 Minimum survival temperature of Aedes eggs after cold treatment. Minimum survival temperature in comparison to duration of treatment for European eggs which have undergone a diapause and non-diapausing eggs of Ae. albopictus and tropical eggs of Ae. albopictus and Ae. aegypti. Eggs of European Ae. albopictus which passed through a diapause survive lower minimum temperatures than non-diapausing eggs when exposed for more than 12h, whereas no differences occurred for short exposure (1h). Eggs of tropical Ae. albopictus survive lower minimum temperatures than Ae. aegypti eggs when exposed for $1 \mathrm{~h}$, whereas no differences occurred for longer exposure $(>8 \mathrm{~h})$.

Carlo permutation procedure of the slopes of the linear regression.

\section{Duration of exposure}

Survival was mainly influenced by temperature $(\mathrm{F}=329.2$, $\mathrm{df}=1, \mathrm{p}<0.001$ ). In comparison to temperature, the duration of exposure only had a minor impact on the hatching rate $(\mathrm{F}=16.2, \mathrm{df}=1, \mathrm{p}<0.001)$. The duration of the cold treatment only significantly influenced the hatching response at the thermal limits of survival for each strain/ species $(\mathrm{F}=5.6, \mathrm{df}=1, \mathrm{p}=0.031)$ but not at $0^{\circ} \mathrm{C}(\mathrm{F}=0.1, \mathrm{df}$ $=1, \mathrm{p}=0.730$ ).

\section{Hatching success after a cold treatment}

Hatching success after the cold treatment was significantly increased in European eggs that have undergone a diapause compared to non-diapausing eggs $(\mathrm{F}=14.7, \mathrm{df}=$ 3 , $\mathrm{p}<0.001$; Figure 2). Differences within the same geographical range but between species (tropical $A e$. albopictus and Ae. aegypti) were less pronounced than differences between geographically different strains of the same species (tropical and European Ae. albopictus). Hatching success of European Ae. albopictus after the total cold treatment was $45 \%$ for eggs after diapause and $30 \%$ in non-diapausing eggs. Only eggs of the European strain hatched after exposure to $-12^{\circ} \mathrm{C}$ for $1 \mathrm{~h}$ : Eggs after a diapause showed a high-hatching success (75\%), where as hatching success was decreased in nondiapausing eggs (10\%). Tropical Ae. albopictus and Ae. aegypti total hatching success was 19 and 25\%, respectively. Surprisingly, hatching of one tropical Ae. albopictus egg occurred after exposure to $-10^{\circ} \mathrm{C}$ for $1 \mathrm{~h}$. The hatching success of Ae. aegypti was almost unaffected when exposed to $-7^{\circ} \mathrm{C}$ for $1 \mathrm{~h}$, whereas an extension of the $-7^{\circ} \mathrm{C}$ cold period for more than $1 \mathrm{~h}$ or a further reduction of temperature down to $-10^{\circ} \mathrm{C}$ caused a complete breakdown of hatching. Neither Ae albopictus nor Ae. aegypti eggs hatched after being exposed to $-15^{\circ} \mathrm{C}$.

\section{Discussion}

We determined the minimum survival temperature of eggs for two strains of Ae. albopictus and for one strain of Ae. aegypti and showed that the hatching success after the cold treatment was significantly increased in European eggs which have undergone a diapause compared to non-diapausing European eggs after exposure to cold temperatures $\left(0^{\circ} \mathrm{C}\right.$ to $\left.-15^{\circ} \mathrm{C}\right)$, for different durations. Overall, we focused on relatively short exposure times $(1 \mathrm{~h}, 4 \mathrm{~h}$, $8 \mathrm{~h}, 12 \mathrm{~h}$ and $24 \mathrm{~h}$ ), because these are the time spans on which minimum temperatures are available from climatology and meteorology. Consequently, our data can be used to make evidence-based decisions on the temporal 


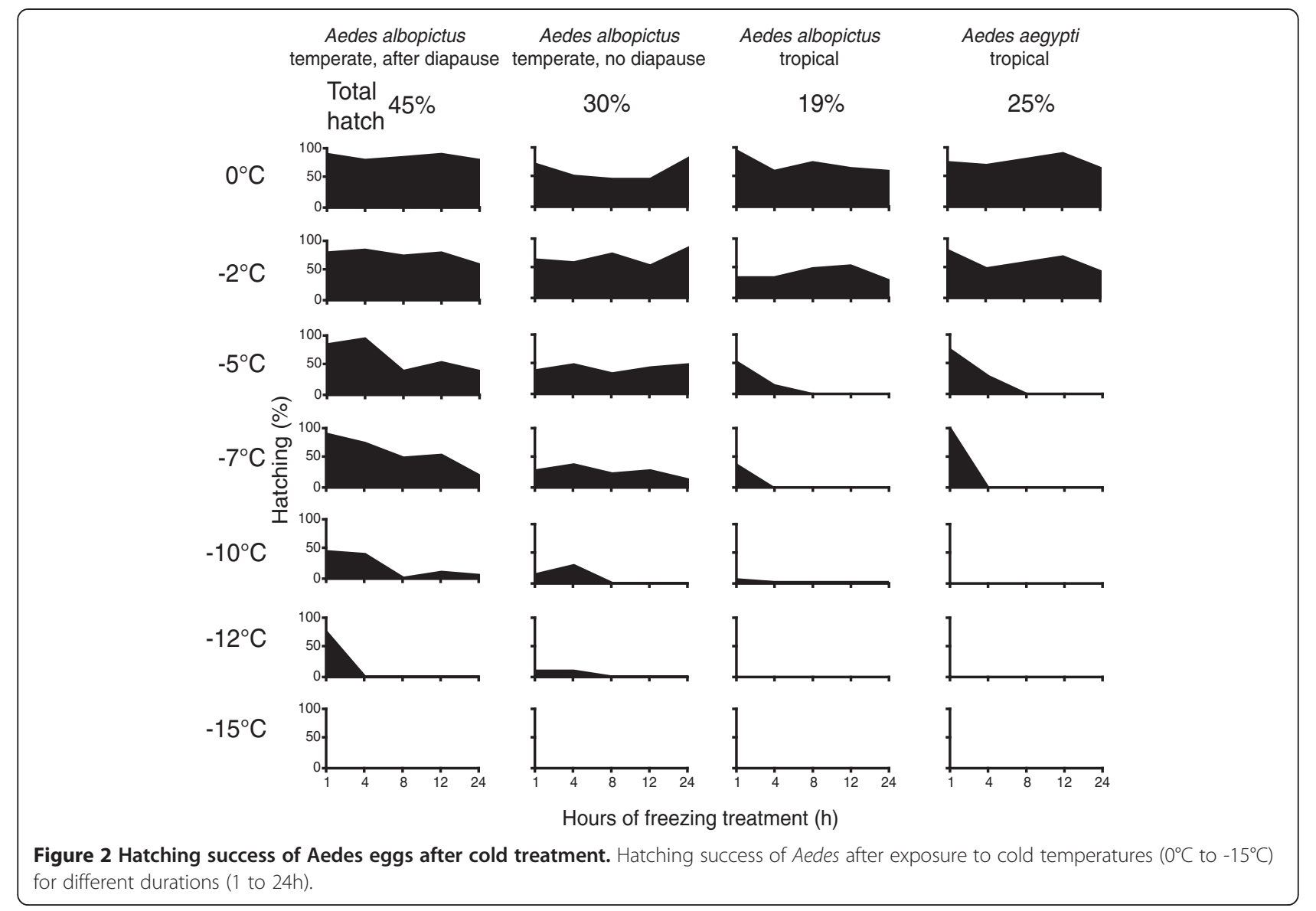

resolution of temperature data needed for modeling approaches. Temperature was the main controlling factor, whereas the duration of the cold treatment only influenced the hatching response significantly at the thermal limits of survival for each strain/species.

To the best of our knowledge there are no comparable studies on the cold tolerance in Ae. albopictus eggs which have undergone a diapause. Previous studies on non-diapausing, non cold-acclimated eggs of a North American strain of Ae. albopictus have shown that no hatching occurs after a $24 \mathrm{~h}$ cold period of $-10^{\circ} \mathrm{C}$ [18]. Our results confirmed this threshold for at which no eggs survive European non-diapausing Ae. albopictus eggs. However, the survival of the European strain in this study is reduced more strongly with decreasing temperature than the survival of the North American: for the European strain we found $50 \%$ egg mortality at $-5^{\circ} \mathrm{C}$, whereas for the North American strain $50 \%$ egg mortality at $-8^{\circ} \mathrm{C}$ was observed [33]. The minimum survival temperature of Ae. aegypti eggs in the field (Houston, Texas, USA) was found to be $7^{\circ} \mathrm{C}$ for a $24 \mathrm{~h}$ cold period [33]. But in nature short term temperature fluctuations occur. Additionally, at one sampling site small scale differences across short distances can be substantial. Ecological complexity contributes to statistical noise. This is why controlled experiments are needed to identify physiologically relevant thresholds.

In the laboratory $-3^{\circ} \mathrm{C}$ for $24 \mathrm{~h}$ was identified as a threshold for Ae. aegypti eggs, respectively [33]. The present results show only a slight increase in the minimum survival temperature for Ae. aegypti $\left(-2^{\circ} \mathrm{C}\right.$ for $\left.24 \mathrm{~h}\right)$. Using a very long-lasting laboratory colony may yield deviating results compared to natural populations. However, such colonies are more appropriate to serve for experimental proof of life cycle thresholds.

It was suggested that the duration of exposure to temperatures below a certain value is an important factor influencing the hatching rate of mosquito eggs [18]. Cold acclimation tends to increase cold hardiness in Ae. albopictus eggs $[29,33]$. In this study, previous cold acclimation was avoided to distinguish between the direct impact of cold temperatures and the duration of exposure (see also [34]). The role of the duration of low temperatures is confirmed at the thermal limits of egg survival by the present study.

Up to now, the risk of Ae. albopictus to establish in Europe was assumed to be relevant only for regions with coldmonth mean temperature of $0^{\circ} \mathrm{C}$ or higher $[35,36]$. The $-5^{\circ} \mathrm{C}$ coldest-month isotherm was suggested to characterize the maximum northward expansion for continental Asia and 
also for North America [37]. The results presented in this study emphasize the ecological importance of absolute minimum temperatures. Up to now, thermal minima are neither adequately considered in environmental niche models nor in epidemiological models. Yet, vector niche modeling is mainly based on long-term average conditions such as annual mean temperature and annual precipitation (e.g. [38]). Winter conditions in terms of the mean minimum temperature of the coldest month and days with ground frost per month are considered in the niche model of Ae. albopictus [39]. Although the incorporation of the absolute minimum temperatures would considerably improve vector risk maps, this would be difficult to implement in large scale projections due to the limited availability of meteorological data in an hourly resolution. Recent epidemiological models consider temperature and season dependent population dynamics of vectors [40]. However, those models start each annual cycle with the same initial number of mosquito individuals. Knowing the minimum survival temperature and survival success after frost events has therefore the potential to improve epidemiological models in temperate zones substantially.

The present study has certain specifics that need to be taken into account: First, the long colonization history of the European Ae. albopictus strain raises the question to what extent this strain actually now represents the characteristics of its founding population. Second, the successful production of diapausing eggs in the laboratory in all females under the recorded circumstances is unlikely. Hatching tests during diapause still showed about $10 \%$ spontaneous hatching.

Nonetheless, winter conditions, or more specifically absolute minimum temperatures, play a decisive role for the distribution limits of a species [41]. Spatial quantification of absolute minimum temperatures, however, is non-trivial. Microclimate may vary up to $10^{\circ} \mathrm{C}$ at small spatial scales [42]. The specific thermal conditions of microsites were found to matter also for the occurrence of aedine species [43]. For these species, indoor breeding sites [44] are adding anthropogenic habitats with specific conditions that do not refer to landscape traits. Thus, it would be naive to concentrate on natural and semi-natural site conditions alone.

Future studies should pay attention to winter conditions by incorporating realistic freeze-thaw cycles to identify how far these temperature fluctuations are affecting egg survival. Furthermore, the knowledge on winter survival of viruses such as dengue and Chikungunya within the eggs of vector insects is of utmost importance and should be intensively addressed in future research.

\section{Conclusions}

Until now, low temperatures have not been considered adequately in the modeling of vector species. Here, low temperature thresholds for aedine mosquito egg survival were detected. The compilation of risk maps for temperate regions can substantially be improved by considering areas where an establishment of a vector population is unlikely due to winter conditions (see Additional file 1).

\section{Additional file}

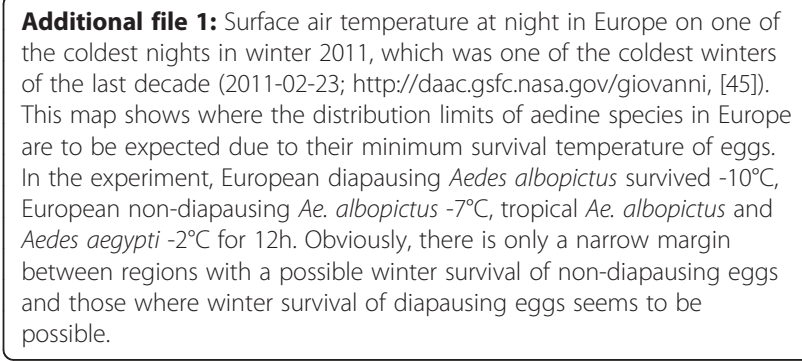

Competing interests

The authors declare that they have no competing interests.

\section{Acknowledgements}

This study would not have been possible without Romeo Bellini who provided the eggs of Ae. albopictus from Northern Italy. In particular, we are grateful to Manuel Steinbauer for valuable comments on the statistical analysis. Laboratory work was strongly supported by Sebastian Hohmeyer and Sven Boese. The authors also thank the 'Bavarian State Ministry of the Environment and Public Health' for their financial support in the project "Vector-borne infectious diseases in climate change investigations (VICCI study)" and the 'Bavarian Food and Health Safety Authority' for coordination of the project. This publication was funded by the German Research Foundation (DFG) and the University of Bayreuth in the funding programme Open Access Publishing.

\section{Author details}

${ }^{1}$ Department of Biogeography, University of Bayreuth, Universitaetsstrasse 30, D-95447 Bayreuth, Germany. ${ }^{2}$ Biogents AG, Department of Zoology, University of Regensburg, Universitaetsstrasse 31, D-93053 Regensburg, Germany.

\section{Authors' contributions}

ST participated in the design of the study, carried out the cold treatment of eggs, performed the statistical analysis and drafted the manuscript. UO carried out the induction of diapause in mosquito eggs. DF helped to draft the manuscript. JK conceived of the study and participated in the performance of the statistical analysis. CB coordinated the study and helped to draft the manuscript. All authors read and approved the final manuscript.

Received: 17 April 2012 Accepted: 23 May 2012

Published: 23 May 2012

\section{References}

1. Gale P, Brouwer A, Ramnial V, Kelly L, Kosmider R, Fooks AR, Snary EL: Assessing the impact of climate change on vector-borne viruses in the EU through the elicitation of expert opinion. Epidemiol Infect 2010, 138:214-225.

2. Mills JN, Gage KL, Khan AS: Potential Influence of Climate Change on Vector-Borne and Zoonotic Diseases: A Review and Proposed Research Plan. Environ Health Perspect 2010, 118:1507-1514.

3. Capelli G, Drago A, Martini S, Montarsi F, Soppelsa M, Delai N, Ravagnan S, Mazzon L, Schaffner F, Mathis A, Di Luca M, Romi R, Russo F: First report in italy of the exotic mosquito species Aedes (Finlaya) koreicus, a potential vector of arboviruses and filariae. Parasites \& Vectors 2011, 4:188.

4. Medlock JM, Hansford KM, Schaffner F, Versteirt V, Hendrickx G, Zeller $H$, van Bortel W: A Review of the Invasive Mosquitoes in Europe: Ecology, Public Health Risks, and Control Options. Vector-Borne Zoonotic Dis 2012, 12. ahead of print. 
5. Gratz NG: Critical review of the vector status of Aedes albopictus. Med Vet Entomol 2004, 18:215-227.

6. Rezza GL, Nicoletti R, Angelini R, Romi R, Finarelli AC, Panning M, Cordioli P, Fortuna C, Boros S, Magurano F, Silvi G, Angelini P, Dottori M, Ciufolini MG, Majori G, Cassone A: Infection with chikungunya virus in Italy: an outbreak in a temperate region. Lancet 2007, 370:1840-1846.

7. Schmidt-Chanasit J, Haditsch M, Schöneberg I, Günther S, Stark K, Frank C: Dengue virus infection in a traveller returning from Croatia to Germany. Euro Surveill 2010, 15(40):pii=19677.[http://www.eurosurveillance.org/ ViewArticle.aspx?Articleld=19677.]

8. Benedict MQ, Levine RS, Hawley WA, Lounibos LP: Spread of the tiger: Global risk of invasion by the mosquito Aedes albopictus. Vector Borne Zoonotic Dis 2007, 7:76-85.

9. Raharimalala FN, Ravaomanarivo LH, Ravelonandro P, Rafarasoa LS, Zouache K, Tran-Van V, Mousson L, Failloux AB, Hellard E, Moro CV, Ralisoa BO, Mavingui P: Biogeography of the two major arbovirus mosquito vectors, Aedes aegypti and Aedes albopictus (Diptera, Culicidae), in Madagascar. Parasites \& Vectors 2012, 5:56

10. Teng HJ, Apperson CS: Development and survival of immature Aedes albopictus and Aedes triseriatus (Diptera: Culicidae) in the laboratory: effects of density, food, and competition on response to temperature. J Med Entomol 2000, 37:40-52.

11. Alto BW, Juliano SA: Temperature effects on the dynamics of Aedes albopictus (Diptera: Culicidae) populations in the laboratory. J Med Entomol 2001, 38:548-556.

12. Alto BW, Juliano SA: Precipitation and temperature effects on populations of Aedes albopictus (Diptera: Culicidae): implications for range expansion. J Med Entomol 2001, 38:646-656.

13. Toma L, Severini F, Di Luca M, Bella A, Romi R: Seasonal patterns of oviposition and egg hatching rate of Aedes albopictus in Rome. J Am Mosa Contr Assoc 2003, 19:19-22.

14. Roiz D, Neteler M, Castellani C, Arnoldi D, Rizzoli A, Baylis M: Climatic Factors Driving Invasion of the Tiger Mosquito (Aedes albopictus) into New Areas of Trentino. Northern Italy. PLOS One 2011, 6:e14800.

15. Delatte H, Gimonneau G, Triboire A, Fontenille D: Influence of temperature on immature development, survival, longevity, fecundity, and gonotrophic cycles of Aedes albopictus, vector of chikungunya and dengue in the Indian Ocean. J Med Entomol 2009, 46:33-41.

16. Juliano S, O'Meara G, Morrill J, Cutwa M: Desiccation and thermal tolerance of eggs and the coexistence of competing mosquitoes. Oecologia 2002, 130:458-469.

17. Fischer S, Alem IS, de Majo MS, Campos RE, Schweigmann N: Cold season mortality and hatching behavior of Aedes aegypti L. (Diptera: Culicidae) eggs in Buenos Aires City, Argentina. J Vector Ecol 2011a, 36:94-99.

18. Hanson SM, Craig CB: Aedes albopictus (Diptera, Culicidae) eggs - field survivorship during northern Indiana winters. J Med Entomol 1995 32:599-604.

19. Mitchell C: Geographic spread of Aedes albopictus and potential for involvement in arbovirus cycles in the Mediterranean Basin. J Vect Ecol 1995, 20:44-58.

20. Hawley WA: The biology of Aedes albopictus. J Am Mosq Contr Assoc 1988, 1(Suppl):1-39.

21. Urbanski JM, Benoit JB, Michaud MR, Denlinger DL, Armbruster P: The molecular physiology of increased egg desiccation resistance during diapause in the invasive mosquito, Aedes albopictus. Proc $R$ Soc B-Biol SC 2010, 277:2683-2692.

22. Jylhä K, Fronzek S, Tuomenvirta H, Carter TR, Ruosteenoja K: Changes in frost, snow and Baltic sea ice by the end of the twenty-first century based on climate model projections for Europe. Clim Change 2008, 86:441-462.

23. Jentsch A, Beierkuhnlein C: Research frontiers in climate change: effects of extreme meteorological events on ecosystems. CR Geoscience 2008, 340:621-628.

24. Kodra E, Steinhaeuser K, Ganguly AR: Persisting cold extremes under 21stcentury warming scenarios. Geophys Res Lett 2011, 38:L08705.

25. Lampman R, Slamecka M, Krasavin N, Kunkel K, Novak R: Culex Population Dynamics and West Nile Virus Transmission in East-Central Illinois. J Am Mosa Contr Assoc 2006, 22:390-400.

26. Bale JS, Hayward SAL: Insect overwintering in a changing climate. J Exp Biol 2010, 213:980-994.
27. Wang R: Observations on the influence of photoperiod on egg diapause in Aedes albopictus Skuse. Acta Entomologica Sinica 1966, 15:75-77.

28. Mori A, Oda T, Wada Y: Studies on the egg diapause and overwintering of Aedes albopictus in Nagasaki. Trop Med 1981, 23:79-90.

29. Hanson SM, Craig CB: Cold Acclimation, Diapause, and Geographic Origin Affect Cold Hardiness in Eggs of Aedes albopictus (Diptera: Culicidae). J Med Entomol 1994, 31:192-201.

30. Novak RJ, Shroyer DA: Eggs of Aedes triseriatus and Ae. hendersoni: a method to stimulate optimal hatch. Mosq News 1978, 38:515-521.

31. R Development Core Team: $R$ : A language and environment for statistical computing. Vienna, Austria: R Foundation for Statistical Computing; 2011 [http://www.R-project.org/].

32. Jurasinski G: simba - A collection of functions for similarity analysis of vegetation data. $R$ package version 0.3-3.: ; 2011 [http://www.r-project.org, http://www2.auf.uni-rostock.de/loe/ma/gerald_forsch.html. GFZ Scientific Technical Reports STR10/10: 129-133]

33. Hanson SM, Craig CB: Relationship between cold hardiness and supercooling point in Aedes albopictus eggs. J Am Mosq Contr Assoc 1995, 11:35-38.

34. Mogi M: Variation in cold hardiness of nondiapausing eggs of nine Aedes (Stegomyia) species (Diptera: Culicidae) from eastern Asia and Pacific islands ranging from the tropics to the cool-temperate zone. J Med Entomol 2011, 48:212-222.

35. Medlock JM, Avenell D, Barrass I, Leach S: Analysis of the potential for survival and seasonal activity of Aedes albopictus (Diptera: Culicidae) in the United Kingdom. J Vect Ecol 2006, 31:292-304.

36. Roiz D, Rosà R, Arnoldi D, Rizzoli A: Effects of temperature and rainfall on the activity and dynamics of host-seeking Aedes albopictus females in Northern Italy. Vector Borne Zoonotic Dis 2010, 10:811-816.

37. Nawrocki SJ, Hawley WA: Estimation of the northern limits of distribution of Aedes albopictus in North America. J Am Mosa Contr Assoc 1987, 3:314-317.

38. Fischer D, Thomas SM, Niemitz F, Reineking B, Beierkuhnlein C: Projection of climatic suitability for Aedes albopictus Skuse (Culicidae) in Europe under climate change conditions. Glob Planet Change 2011, 78:54-64.

39. Medley KA: Niche shifts during the global invasion of the Asian tiger mosquito, Aedes albopictus Skuse (Culicidae), revealed by reciprocal distribution models. Glob Ecol Biogeogr 2010, 19:122-133.

40. Rubel F, Brugger K, Hantel M, Chvala-Mannsberger S, Bakonyi T, Weissenböck H, Nowotny N: Explaining Usutu virus dynamics in Austria: Model development and calibration. Prev Vet Med 2008, 85:166-186.

41. Kreyling J: Winter climate change: a critical factor for temperate vegetation performance. Ecology 2010, 91:1939-1948.

42. Suggitt AJ, Gillingham PK, Hill JK, Huntley B, Kunin WE, Roy DB, Thomas CD: Habitat microclimates drive fine-scale variation in extreme temperatures. Oikos 2011, 120:1-8.

43. Lounibos LP, O'Meara GF, Juliano SA, Nishimura N, Escher RL, Reiskind MH, Cutwa M, Greene K: Differential Survivorship of Invasive Mosquito Species in South Florida Cemeteries: Do Site-Specific Microclimates Explain Patterns of Coexistence and Exclusion? Ann Entomol Soc Am 2010 103:757-770.

44. Romi R, Severini F, Toma L: Cold acclimation and overwintering of female Aedes albopictus in Roma. J Am Mosa Contr Assoc 2006, 22:149-151.

45. Acker JG, Leptoukh $\mathrm{G}$ : Online analysis enhances use of NASA Earth Science Data. Eos Trans AGU 2007, 88:14-17.

doi:10.1186/1756-3305-5-100

Cite this article as: Thomas et al:: Low-temperature threshold for egg survival of a post-diapause and non-diapause European aedine strain, Aedes albopictus (Diptera: Culicidae). Parasites \& Vectors 2012 5:100. 